\title{
Study on the Influencing Factors of China's Commercial Health Insurance in the New Era
}

\author{
Yumeng Huang \\ School of Economics and Management, China University of Geosciences (Wuhan),Wuhan, China
}

HYM2537658421@163.com

\begin{abstract}
As one of the important components of China's basic medical security system, commercial health insurance not only provides supplementary security for people in addition to basic medical insurance, but also has great significance for the stable development of society. Using a linear regression model based on the panel data of 31 provinces, municipalities and autonomous regions from 2011 to 2019, this paper summarized the problems and describes status quo of the development of China's commercial health insurance to empirically analyze the influencing factors of China's commercial health insurance and provide suggestions to promote its good development.
\end{abstract}

Keywords: The New Era; Commercial Health Insurance; Influencing Factors.

\section{Research Background and Significance}

In recent years, with policy support and economic growth, commercial health insurance, as a powerful supplement to China's medical insurance system, has witnessed a continuous rapid development. In the Report to the 19th National Congress of the Communist Party of China, General Secretary Xi Jinping clearly pointed out that we should implement the Healthy China Strategy and make concerted efforts from all aspects to provide all-round and full-cycle health services to the people. With the increasing trend of population aging, the development of health and elderly care industry has been widely concerned by all walks of life, which further proves the importance of the new model of coordinated development of insurance industry and health and elderly care industry. In early 2020, the COVID-19 pandemic raised the national attention on health insurance. In this context, with the guidance of relevant national policy documents, the innovation and maturity of scientific and technological products, the diversification of public demands, and the close attention of capital and market, the health insurance industry ushered in a new situation of innovation and development.

\section{Literature Review}

As the reform of China's social medical insurance system deepens, commercial health insurance has developed rapidly, which attracted increasing attention of scholars. So far, abundant research achievements have been achieved in this field from diversified perspectives.

\subsection{Research on Influencing Factors of Commercial Health Insurance}

Many scholars have studied the factors influencing commercial health insurance demand from various aspects such as economy, society, population structure, etc. Tian Xiujie [1] (2017) found that the medical insurance premium income was positively correlated with the disposable personal income of urban residents as well as the health insurance coverage, while the elderly population and rural employment personnel were oppositely changed compared with medical insurance premium income. The study of Ni Lan et al. [2] (2018) indicated that the factors significantly influencing the demand for commercial health insurance included the per capita disposable income of urban residents, basic medical insurance fund income of urban employees, elderly population bring-up ratio, and per capita outpatient expenses. The research of Huang Xiuquan et al. [3] (2019) concluded that in general, the medical and health financial expenditure had a "substitution effect" on the development of commercial health insurance. Yuan Cheng [4] (2020) found that air pollution had a positive effect on residents' future purchase decisions of the commercial health insurance, but inhibited the current 
health insurance purchase, which was more significant for residents with stronger risk awareness, indicating that Chinese residents were not forward-looking in the commercial health insurance consumption at present.

\subsection{Research Methods of Commercial Health Insurance}

Li Yaguo et al. [5] (2017) studied the multiple factors influencing the demand growth of commercial health insurance by constructing a C-D function model. Wei Xiao [6] (2018) empirically examined the effects of marriage, family education level, and family size on commercial health insurance by mining Chinese Household Financial Survey database (CHFS) and using Probit model and Tobit model. Jiang Qiao [7] (2020) studied the demand for commercial health insurance in Henan Province from various aspects including individual factors, social factors, and internal factors of the health insurance industry with the application of systematic GMM model based on panel data from 2008 to 2018.

Based on existing relevant literature, the paper, summarized the development of commercial health insurance in provinces and cities in China in the past decade, screened out a number of indicators that may affect its development and analyzed their impact, and further put forward suggestions and countermeasures for the development of China's commercial health insurance in the new era.

\section{The Development Status of Commercial Health Insurance in China}

\subsection{Rapid Development of the Health Insurance Industry and Increasing Public Willingness to Purchase Health Insurance}

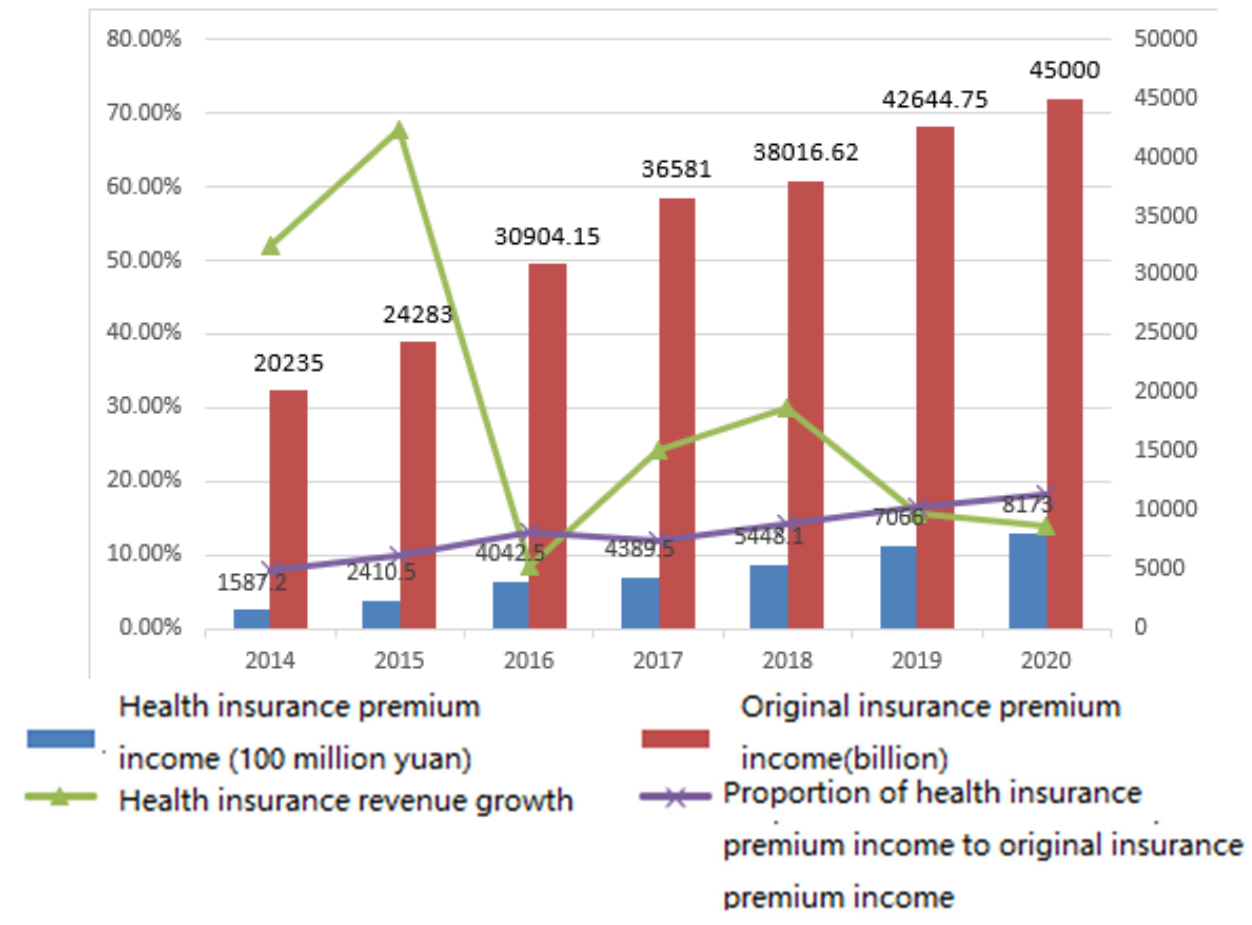

Figure 1. The Proportion of China's Health Insurance Premium Income in Original Insurance Premium Income from 2014 to 2020

Data source: Based on relevant data from China Insurance Regulatory Commission and Zhiyan Consulting.

At present, the original premium income of health insurance in China has witnessed a year-onyear increase.

According to data from China Insurance Regulatory Commission (CIRC) and Zhiyan Consulting, the original premium income of commercial health insurance increased rapidly from 158.72 billion 
yuan in 2010 to 817.3 billion yuan in 2020 , accounting for $7.84 \%$ to $18.2 \%$ of the total respectively. At the same time, from 2010 to 2019, the number of insurance employees in China increased from 686,000 to $1,233,000$, and the number of insurance institutions increased from 142 to 235, both of which realized a doubling growth trend. According to the information of CIRC, from 2016 to 2018, the number of insurance policies in China tripled from 9.5 billion to 29 billion. According to the 2020 Chinese Family Insurance Demand Survey Report, among the respondents who have purchased insurance, each family member holds 1.17 policies and the whole family holds 3.62 policies on average. All the data above prove a continuous and steady development of China's health insurance industry and an overall increasing trend of public willingness to purchase health insurance.

\subsection{Increasing Insurance Depth and Density with Regional Imbalance}

In general, the insurance depth and density of commercial health insurance of China lags behind that of developed countries, with low proportion of compensation expenditure, so the supplementary security function of health insurance is limited. According to the data from the Insurance Industry Association of China, in 2019, the insurance depth in mainland China was $4.4 \%$ with a insurance density of $\$ 407$ per person. However, in countries with mature insurance markets such as the United Kingdom and Japan, the insurance depth was as high as $10.8 \%$ and $8.2 \%$ with a insurance density up to $\$ 4,359$ and $\$ 3,554,11$ times and 9 times of that of China, respectively. In addition, the problem of insufficient supplementary security of medical insurance persists and there is still a large space for development.

\subsection{Increasingly Diversified Insurance Categories and Constantly Optimized Insurance Services}

China's commercial health insurance has experienced transformations from simple product forms to complex ones and from partial insurance liability to comprehensive one. Meanwhile, the insurance liability has been constantly improved, and the product setting optimized and innovated.

Among the current popular commercial health insurance products, large enterprises present prominent comprehensive strength and high product premium, while small and medium-sized enterprises are more likely to highlight the cost-effective advantages of their products. Consumers can choose the products they need according to their own situation, with a comprehensive consideration of factors including price, brand, insurance period, additional services, the diversification of insurance liability, etc.

\subsection{Rapid Development of Internet Health Insurance and Increasing Proportion of Sales Revenue from Third-party Platforms}

In the new era, with the rise of Internet technology, people have gradually mastered more efficient and convenient ways to obtain information, which has alleviated information asymmetry and promoted the development of the new mode of "Internet plus health insurance". From 2015 to 2019, the premium income of Internet health insurance increased from 1.03 billion yuan to 23.6 billion yuan, accounting for $0.7 \%$ to $12.7 \%$ of the total premium income of health insurance. In 2020 , due to the epidemic, the offline business of health insurance in China was hindered, while the innovative development of Internet insurance was greatly promoted. "Internet plus health insurance" achieved $14.1 \%$ of the premium income, up to 35.73 billion yuan. In addition, Third-party platforms such as WeSure and Ant Financial accounted for $88.7 \%$ of the total revenue, forming a sharp contrast to the self-run platforms of insurance companies that only accounted for $11.3 \%$ of the total sales.

\subsection{High Market Concentration and Increasingly Fierce Competition in Health Insurance Industry}

According to public data, by 2019, China had had 91 and 73 individual insurance companies operating commercial health insurance and property insurance respectively. However, in terms of 
revenue, life insurance companies accounted for $88 \%$ of the original insurance premium income, while property insurance companies only accounted for $12 \%$.

The market concentration of life insurance industry is quite high, with the top 10 companies accounting for $78 \%$ of the market. In recent years, the Matthew effect has been quite obvious. Several leading enterprises has covered most of the profits of the industry, with the income of health insurance rising year by year. However, many small and medium-sized enterprises have suffered from poor operation and meager profits, with urgent needs for transformation.

\section{Empirical Analysis of Influencing Factors of Commercial Health Insurance Development in China}

In the new era, China's commercial health insurance has developed to a new stage, facing both risks and opportunities. This section aims to examine the factors that influence the development of commercial health insurance and establish a regression model to find out the most critical influencing factors, so as to provide strong support for developing subsequent coping strategies.

\subsection{Data Source}

The data used in this study are mainly from China Insurance Yearbook (2011-2019), the website of China Banking and Insurance Regulatory Commission, the website of National Bureau of Statistics, and EPSDATA (global statistical data/analysis platform), including commercial health original insurance premium annual income (revenue), government health expenditure proportion, sex ratio, number of medical institutions, number of beds in medical institutions, number of health technical personnel, divorce rate, urbanization level, industrial structure level, per capita health care expenditure in urban areas, gross domestic product (GDP), elderly population bring-up ratio, and the proportion of the student number in universities of higher education to the total population in 31 provinces, municipalities, and autonomous regions from 2011 to 2019.

\subsection{Model Specification}

In order to explore the various influencing factors of the commercial health insurance demand in China, this paper constructed a fixed effect model.

$$
\begin{aligned}
\text { revenue }_{i, t}= & \alpha_{0}+\alpha_{1} w_{1 i, t}+\alpha_{2} w_{2_{i, t}}+\alpha_{3} w_{3_{i, t}}+\alpha_{4} w_{4 i, t}+\alpha_{5} w_{5_{i, t}}+\alpha_{6} w_{6 i, t}+\alpha_{7} w_{7 i, t}+ \\
& \alpha_{8} w_{8_{i, t}}+\alpha_{9} w_{9_{i, t}}+\alpha_{10} w_{10_{i, t}}+\alpha_{11} w_{11_{i, t}}+u_{i}+\varepsilon_{i, t}
\end{aligned}
$$

Where $i$ represents region, $t$ represents year, the explained variable is commercial health original insurance premium annual income (revenue) in this region, explanatory variables include government health expenditure proportion $\left(w_{1}\right)$, sex ratio $\left(w_{2}\right)$, number of medical institutions $\left(w_{3}\right)$, number of beds in medical institutions $\left(w_{4}\right)$, number of health technical personnel $\left(w_{5}\right)$, divorce rate $\left(w_{6}\right)$, urbanization level $\left(w_{7}\right)$, industrial structure level $\left(w_{8}\right)$, per capita health care expenditure in urban areas $\left(w_{9}\right)$, regional gross domestic product $\left(w_{10}\right)$, elderly population bring-up ratio $\left(w_{11}\right), \mathrm{u}_{\mathrm{i}}$ controls individual fixed effect in the region, and $\varepsilon_{\mathrm{i}, \mathrm{t}}$ refers to the residual term.

Each variable is defined as follows:

(1) Commercial health insurance premium income. It is a key index to measure the size of the market, which reflects people's demand for commercial health insurance, and since demand is exactly the driving force of the development of insurance, the greater the demand is, the more optimistic the development prospect of commercial health insurance will be.

(2) Government health expenditure proportion. The emphasis the government given to public health cause can influence the public attention to their own health to a great extent. The heavy investment of government in the public health cause may not only lead to the "crowd out" effect on 
commercial health insurance, but also improve the public health perception and commercial health insurance demand. The proportion of government health expenditure in total expenditure serves as an important indicator to measure the emphasis on public health cause, so the paper takes it as one of the explanatory variables.

(3) Sex ratio. According to the related research, males and females suffer from the potential threats of disease at varying degrees. Besides, there are also differences in their risk preferences, health condition perceptions, and health insurance demand. Therefore, sex can be regarded as a influencing factor of commercial health insurance development situation.

(4) Number of medical institutions. The number of medical institutions in a region represents the medical level of this region to a large extent, which is closely related to the resident health condition in this region and naturally affects the enthusiasm of residents to purchase commercial health insurance. Therefore, this author takes it as one of the explanatory variables.

(5) Number of beds in medical institutions. The number of beds in medical institutions in a region to a certain extent is related to the difficulty of local residents' access to medical service and their cost of time, money, etc., which affect their demand for commercial health insurance. Therefore, it is also taken as one of the explanatory variables.

(6) Number of health technical personnel. The number of health technical personnel in a region in a region affects the access of difficult local residents to medical service from another perspective. Before reaching the saturation, the more the technical personnel, the higher the medical service cost, which will be passed on to the residents who accept the medical service. Therefore, this number can also be selected as an explanatory variable in this study as it affects the residents' attitude to commercial health insurance.

(7) Divorce rate. Family environment tends to be an important factor that affect people's risk perception. After establishing a family, people's perception of their health risk is highly possible to change, which can affect the demand for commercial health insurance. Thus, it can be taken as an explanatory variable in the empirical analysis.

(8) Urbanization level. It represents a lot of factors such as economic development level, health care level, education level, etc. Generally, the high urbanization level represents advanced economy, health care, education, etc., which can obviously and significantly influence the attitude and demand for commercial health insurance. Therefore, urbanization level can be selected as an explanatory variable in the study.

(9) Industrial structure level. It refers to the proportion of agriculture, industry and service industry in the whole industry. Cities with different leading industries have different development conditions and directions, which lead to different attitudes and demands of residents towards commercial health insurance. Therefore, the author selects it as an explanatory variable.

(10) Per capita health care expenditure in urban areas. Similar to government health expenditure proportion, per capita health care expenditure in urban areas is a measurement of the emphasis the government given to public health care and medical security. However, because of the relatively slow pace of rural medical security construction, health care expenditure is focused on urban areas. Therefore, urban areas can more accurately respond to the government's investment on health care and the per capita health care expenditure in urban areas is selected as an explanatory variable.

(11) Regional gross domestic product (GDP). It is one of the most common indicators used to measure the economic development level of countries or regions, which has significant influence on people's consciousness, demand, and willingness to purchase commercial health insurance. Therefore, the author also selects regional GDP as an explanation of the variables in the empirical analysis.

(12) Elderly population bring-up ratio. It refers to the ratio of the elderly population (65 years old as a cut-off point) to the working-age population, which represents the number of the elderly that every 100 working-age people need to afford. To some extent, it reflects the degree of the pressure of the society, families and individuals to bring up the elderly as well as people's economic burden and life stress, which greatly influence people's willingness to purchase commercial health insurance. So we add it into the influencing factors of the study. 
Table 1. Definitions of Variables Related to Fixed Effect Model of Influencing Factors of Commercial Health Insurance

\begin{tabular}{|c|c|c|}
\hline & Variable & Definition \\
\hline 1 & Insurance premium income & $\begin{array}{l}\text { Commercial health insurance premium total income in a region in a year } \\
\text { (Unit: } 100 \text { million yuan) }\end{array}$ \\
\hline 2 & $\begin{array}{l}\text { Government health expenditure } \\
\text { proportion }\end{array}$ & $\begin{array}{l}\text { The ratio of government health expenditure proportion to total expenditure } \\
\text { in a region in a year (Unit: \%) }\end{array}$ \\
\hline 3 & Sex ratio & $\begin{array}{c}\text { The ratio of male population to female population in a region in a year } \\
\text { (Unit: \%) }\end{array}$ \\
\hline 4 & Number of medical institutions & The number of medical institutions in a region in a year (Unit: one) \\
\hline 5 & $\begin{array}{l}\text { Number of beds in medical } \\
\text { institutions }\end{array}$ & $\begin{array}{c}\text { The total number of beds in medical institutions in a region in a year (Unit: } \\
\text { ten thousand) }\end{array}$ \\
\hline 6 & $\begin{array}{l}\text { Number of health technical } \\
\text { personnel }\end{array}$ & $\begin{array}{l}\text { The total number of health technical personnel in a region in a year (Unit: } \\
\text { ten thousand) }\end{array}$ \\
\hline 7 & Divorce rate & $\begin{array}{l}\text { The ratio of the divorced population to population with a current or past } \\
\text { marriage over } 15 \text { years old in a region in a year (Unit: \%) }\end{array}$ \\
\hline 8 & Urbanization level & $\begin{array}{l}\text { The ratio of the urban population to the total population in a region in a year } \\
\text { (Unit: \%) }\end{array}$ \\
\hline 9 & Industrial structure level & $\begin{array}{l}\text { The proportion of the tertiary industry added value in the GDP in a region in } \\
\text { a year (Unit: \%) }\end{array}$ \\
\hline 10 & $\begin{array}{l}\text { Per capita health care } \\
\text { expenditure in urban areas }\end{array}$ & $\begin{array}{l}\text { Per capita health care expenditure in urban areas in a region in a year (Unit: } \\
\text { yuan) }\end{array}$ \\
\hline 11 & Regional gross domestic product & Gross domestic product in a region in a year (Unit: 100 million yuan) \\
\hline 12 & Elderly population bring-up ratio & The ratio of the elderly population to the working-age population (Unit: \%) \\
\hline
\end{tabular}

\subsection{Descriptive Statistics}

Table 2. Statistics of Indicators of 31 Provinces, Municipalities and Autonomous Regions in 2019

\begin{tabular}{|c|c|c|c|c|c|}
\hline & $\begin{array}{c}\text { Sample } \\
\text { size }\end{array}$ & Mean & Minimum & Maximum & $\begin{array}{c}\text { Standard } \\
\text { deviation }\end{array}$ \\
\hline $\begin{array}{c}\text { Government health } \\
\text { expenditure proportion }\end{array}$ & 31 & 0.078699652 & 0.055645708 & 0.098795954 & 0.012975669 \\
\hline $\begin{array}{c}\text { Sex ratio (\%) } \\
\text { Number of medical } \\
\text { institutions }\end{array}$ & 31 & 104.6909677 & 96.73 & 123.17 & 5.068746956 \\
\hline $\begin{array}{c}\text { Number of beds in medical } \\
\text { institutions (Unit: ten } \\
\text { thousand) }\end{array}$ & 31 & 28.40967742 & 1.71 & 64651 & 23244.29641 \\
\hline $\begin{array}{c}\text { Number of health technical } \\
\text { personnel (Unit: ten } \\
\text { thousand) }\end{array}$ & 31 & 32.72225806 & 2.09 & 79.26 & 20.78796153 \\
\hline Divorce rate & 31 & 0.030524702 & 0.015919062 & 0.059831336 & 0.011182981 \\
\hline Urbanization level & 31 & 0.60852794 & 0.316239316 & 0.883031301 & 0.115787959 \\
\hline Industrial structure level & 31 & 0.538296133 & 0.464615632 & 0.836882954 & 0.074831798 \\
\hline $\begin{array}{c}\text { Per capita health care } \\
\text { expenditure in urban areas } \\
\text { (Unit: yuan) }\end{array}$ & 31 & 2571.489596 & 1903.065421 & 7077.747453 & 1043.540357 \\
\hline $\begin{array}{c}\text { Regional gross domestic } \\
\text { product (Unit: 100 million } \\
\text { yuan) }\end{array}$ & 31 & 31687.75806 & 1697.8 & 107986.9 & 25848.65225 \\
\hline $\begin{array}{c}\text { Elderly population bring- } \\
\text { up ratio (\%) }\end{array}$ & 31 & 16.80322581 & 8.9 & 23.8 & 3.873627402 \\
\hline $\begin{array}{c}\text { Insurance premium income } \\
\text { (Unit: 100 million yuan) }\end{array}$ & 31 & 227.8709677 & 4 & 857 & 187.2425774 \\
\hline
\end{tabular}


Table 2 shows that there are considerable regional differences in the 12 influencing factors of 31 provinces, municipalities and autonomous regions in 2019. Taking premium income as an example, a maximum of premium income in 2019 was 85.7 billion yuan, while the minimum was only 0.4 billion yuan, with standard deviation up to 187 . These numbers show that there is a huge difference in the development level of commercial health insurance in different regions in China. In addition, the maximum of the number of medical institutions was 20 times the minimum with a standard deviation as high as 23244. The standard deviation of regional gross domestic product was 25849 in gross regional product, which embodies the unbalanced development in the field of commercial health insurance in the new era to some extent.

Table 3 presents the basic data of all possible influencing factors in Beijing from 2011 to 2019. Taking the premium income as an example, the minimum value was only 66.32 , the maximum value was 401 , and the standard deviation was as high as 123.04 , which means that the premium income in Beijing experienced a huge increase from 2011 to 2019, and the annual change was large, indicating that commercial health insurance has made great progress in the past nine years. However, as one of the most developed cities in China, Beijing still falls behind compared with developed countries. Moreover, the development situations of other provinces and cities are more likely to be worse, reflecting that the development of commercial health insurance in China is still not sufficient in the new era.

Table 3. Statistics of Basic Indicators of Each District in Beijing from 2011 to 2019

\begin{tabular}{|c|c|c|c|c|c|}
\hline & $\begin{array}{c}\text { Sample } \\
\text { size }\end{array}$ & Mean & Minimum & Maximum & $\begin{array}{c}\text { Standard } \\
\text { deviation }\end{array}$ \\
\hline $\begin{array}{c}\text { Government health } \\
\text { expenditure proportion }\end{array}$ & 9 & 0.067052628 & 0.062113983 & 0.072137729 & 0.003666328 \\
\hline Sex ratio (\%) & 9 & 104.1544444 & 98.75 & 109.45 & 3.2758858 \\
\hline $\begin{array}{c}\text { Number of medical } \\
\text { institutions }\end{array}$ & 9 & 9818 & 9495 & 10336 & 260.9291091 \\
\hline $\begin{array}{c}\text { Number of beds in medical } \\
\text { institutions (Unit: ten } \\
\text { thousand) }\end{array}$ & 9 & 11.21444444 & 9.47 & 12.78 & 1.112711902 \\
\hline $\begin{array}{c}\text { Number of health technical } \\
\text { personnel (Unit: ten } \\
\text { thousand) }\end{array}$ & 9 & 22.52777778 & 18.19 & 27.12 & 2.934854246 \\
\hline Divorce rate & 9 & 0.023974877 & 0.017533407 & 0.030601922 & 0.004506062 \\
\hline Urbanization level & 9 & 0.863982968 & 0.861812779 & 0.865831012 & 0.001431642 \\
\hline Industrial structure level & 9 & 0.811407274 & 0.784871544 & 0.836882954 & 0.019368193 \\
\hline $\begin{array}{c}\text { Per capita health care } \\
\text { expenditure in urban areas } \\
\text { (Unit: yuan) }\end{array}$ & 9 & 4206.388821 & 2194.741379 & 7077.747453 & 1513.352982 \\
\hline $\begin{array}{c}\text { Regional gross domestic } \\
\text { product (Unit: 100 million } \\
\text { yuan) }\end{array}$ & 9 & 25614.27778 & 17188.8 & 35445.1 & 6279.253013 \\
\hline $\begin{array}{c}\text { Elderly population bring- } \\
\text { up ratio (\%) }\end{array}$ & 9 & 12.91111111 & 10.5 & 16.3 & 2.364024347 \\
\hline $\begin{array}{c}\text { Insurance premium income } \\
\text { (Unit: 100 million yuan) }\end{array}$ & 9 & 220.7161164 & 66.322705 & 401 & 123.0489166 \\
\hline
\end{tabular}

\subsection{Analysis of Statistical Results}

The author selected fixed effects to carry out regression analysis. The regression results are shown in Table 4.

(1) The t-test value of government health expenditure proportion was 2.054936 , which was significant at the level of $10 \%$, indicating that the increased investment of government in public health cause has a positive effect on the development of commercial health insurance in China. Increased government investment in the field of public health will motivate people to pay attention to health 
issues, further enhance health awareness, and motivate people to purchase commercial health insurance, thus promoting the industry development.

(2) The t-test value of the sex ratio was -1.680129 , which did not pass the significance test. Therefore, it can be concluded that the gender difference has no significant impact on the development of commercial health insurance in China.

(3) Compared with the significant value of $5 \%$, the t-test value of the number of medical institutions was 3.084362, indicating its promoting effect on the development of commercial health insurance in China. Generally, the number of medical institutions and medical level are positively related, and the improvement of the medical level in a region will also promote the improvement of people's health awareness. Therefore, it can be concluded that the increase of the number of medical institutions will promote the development of China's commercial health insurance.

(4) The t-test value of the number of beds in medical institutions was 1.961386, which was significant test at the $10 \%$ level. The regression results showed a negative relationship between the number and commercial health insurance income. However, in the real situation, the number of beds in medical institutions is strongly positive correlated with the number of medical institutions, which means that the increase of the number of beds will promote the development of commercial health insurance. Therefore, the impact the number of beds in medical institutions should be confirmed in further research.

(5) The t-test value of the number of health technical personnel was 3.278742, which passed the significance test at the $1 \%$ level, showing its strong positive impact on the development of commercial health insurance. The reason is similar to the influence caused by the increase in the number of medical institutions. People will have more awareness of insurance with the improvement of medical level and stronger desire to purchase commercial health insurance, which can promote its development.

(6) The t-test value of divorce rate was 2.817036 , which was tested significant at $5 \%$. The regression results showed that divorce rate had a promoting effect on the development of commercial health insurance, this may be rooted in the fact that a lack of marriage can bring a sense of insecurity making people more inclined to purchase insurance to improve their resistance ability for future risks. However, further research is needed to test the mechanism.

(7) The t-test value of urbanization level was 4.604775 , which passed the significance test at the $1 \%$ level, indicating that urbanization level can significantly improve the development of commercial health insurance. Urbanization level represents the number of insured people of commercial health insurance to some extent. The high proportion of insured people in the total can promote the development of commercial health insurance in the region.

(8) The t-test value of industrial structure level was 3.459868, which passed significance test at $1 \%$ level, indicating that the adjustment of industrial structure can significantly affect the development of commercial health insurance. On the one hand, the higher the proportion of tertiary industry in a region is, the higher the level of economic development of the region will be. People tend to pursue a higher level of life quality and are willing to pay for a more comprehensive life security, so the development level of commercial health insurance will be higher. On the other hand, people living in the areas with developed tertiary industry pay more attention to the development of pension and health services, which can provide potential and space for improving commercial health insurance.

(9) The t-test value of per capita health care expenditure in urban areas was 5.610088, which passed the significance test at the level of $1 \%$, indicating its significant positive impact on the development of commercial health insurance in China. The higher the per capita health care expenditure in urban areas is, the better medical service urban residents can enjoy. Therefore, it plays an important role in improving people's health attention and awareness of medical security, promoting the development of commercial health insurance.

(10) The t-test value of GDP was 3.750482, which was significant at $1 \%$ level, indicating that the economic development level of a region has a significant positive effect on the development of commercial health insurance. GDP reflects the national development scale and economic 
development level. The growth of GDP has a significant positive impact on China's health service industry, insurance industry, and elderly service industry.

(11) The t-test value of the elderly population bring-up ratio was -4.07976 , which was significant at $1 \%$ level, indicating that the aggravation of the aging problem has a significant negative impact on the development of commercial health insurance. The higher the elderly population bring-up ratio is, the greater responsibility for people to bring up the elderly will be, which has a certain impact on life quality and narrows the expectation and future planning of health management and health services, thus reducing the investment in commercial health insurance.

Table 4. Regression Analysis Results of Influencing Factors of Commercial Health Insurance

\begin{tabular}{|c|c|c|c|}
\hline Variable & $\begin{array}{c}\text { Regression } \\
\text { Coefficient }\end{array}$ & Variable & $\begin{array}{c}\text { Regression } \\
\text { Coefficient }\end{array}$ \\
\hline $\begin{array}{c}\text { Government health expenditure } \\
\text { proportion }\end{array}$ & $\begin{array}{c}431.213644 \\
(2.054936)^{*}\end{array}$ & Urbanization level & $\begin{array}{c}170.420473 \\
(4.604775)^{* * *}\end{array}$ \\
\hline Sex ratio & $\begin{array}{c}-1.184086 \\
(-1.680129)\end{array}$ & Industrial structure level & $\begin{array}{c}337.040426 \\
(3.459868)^{* * *}\end{array}$ \\
\hline $\begin{array}{c}\text { Number of medical institutions } \\
(3.084362)^{* *}\end{array}$ & $\begin{array}{c}\text { Per capita health care expenditure in } \\
\text { urban areas }\end{array}$ & $\begin{array}{c}0.013752 \\
(5.610088)^{* * *}\end{array}$ \\
\hline $\begin{array}{c}\text { Number of beds in medical } \\
\text { institutions }\end{array}$ & $\begin{array}{c}-1.370386 \\
(-1.961386)^{*}\end{array}$ & Regional gross domestic product & $\begin{array}{c}0.003207 \\
(3.750482)^{* * *}\end{array}$ \\
\hline $\begin{array}{c}\text { Number of health technical } \\
\text { personnel }\end{array}$ & $\begin{array}{c}2.208537 \\
(3.278742)^{* * *}\end{array}$ & Elderly population bring-up ratio & $\begin{array}{c}-4.890799 \\
(-4.07976)^{* * *}\end{array}$ \\
\hline Divorce rate & $\begin{array}{c}919.77465 \\
(2.817036)^{* *}\end{array}$ & & \\
\hline
\end{tabular}

\section{References}

[1] Tian X J. Empirical Analysis of Influence Factors of Commercial Health Insurance Demand in China[A]. Harbin University of Commerce. 2017 North-East Asia Academic Forum (Publication of Scientific Articles) [C]. Harbin University of Commerce: Editorial Board of the North- East Asia Academic Forum, 2017: 4.

[2] Ni L, Feng G Z. The Analysis on the Influence Factors of Commercial Health Insurance Demand Based on the Model of Cross-sectional Fixed Effect [J]. Chinese Health Economics, 2018. (In Chinese).

[3] Huang X Q, Xu X C. Research on the influence of medical and health expenditure on the development of commercial health insurance in China [J]. Wuhan Finance Monthly, 2019, 000(007): 58-63. (In Chinese).

[4] Yuan C, Liu S T. Air pollution, risk perception and commercial health insurance consumption in China [J]. Insurance Studies, 2020(8). (In Chinese).

[5] Li Y G, Song W J. Analysis of the influencing factors of commercial health insurance demand in Jiangxi Province: Based on Ridge Regression and C-D Function [J]. Finance and Economy, 2017, 000(006): 8387. (In Chinese).

[6] Wei X. Effects of marital status on household commercial health insurance participation behavior[J]. Journal of Interdisciplinary Mathematics, 2018, 21(2): 397-407.

[7] Jiang Q. Analysis on the influencing factors of the demand for commercial health insurance in Henan Province [D]. Henan University, 2020. 